\title{
Improving the Stability of the Rock Massif by Choosing Rational Configurations of Workings and Methods of Their Support
}

\author{
Nikolay Bedarev ${ }^{1}$, Oleg Lyubimov ${ }^{2,}$, Arthur Shayhislamov ${ }^{3}$, Natalya Grigorieva $^{1}$, and \\ Asmelash $\mathrm{Abay}^{4}$ \\ ${ }^{1}$ T.F. Gorbachev Kuzbass State Technical University, Prokopyevsk branch, Department of technology and \\ complex mechanization of mining, 653033, Prokopyevsk, Russian Federation \\ ${ }^{2}$ T.F. Gorbachev Kuzbass State Technical University, Department of information and automated \\ manufacturing systems, 650000 Kemerovo, Russian Federation \\ ${ }^{3}$ West Siberian Industrial Engineering, the Directorate, 654000 Novokuznetsk, Russian Federation \\ ${ }^{4}$ College of Natural and Computational Sciences, Department of Earth Science, Mekelle University, \\ P.O.Box.3066, Mekelle, Ethiopia
}

\begin{abstract}
The paper presents simulation results on gypsum-sand mixtures models. The experiments have been carried out simultaneously in three workings of various configurations in the massif before mine cleaning. They show the differences in the redistribution of rock pressure. The authors have identified the ways to improve the study of rock pressure by developing new modeling methods. These methods make it possible to determine changes in deformations of mining massif from the very beginning and during the entire service life of workings, with the fixation of high rock pressure relief zones and stabilization zones, taking into account the time scale.
\end{abstract}

\section{Introduction}

Numerous research works have been devoted to finding the ways of minimizing the affect of the rock pressure redistribution on the stability of the rock massif during the preparatory and treatment works. At the same time, it is well known, that load on the mine working support increases significantly during mining operations in areas of high rock pressure. However, mining and geological conditions as well as mining and technical specifications of the world's mineral deposits are various. In this regard, the studies conducted in relation to specific conditions also differ significantly, and that is why, the research methods are prepared in relation to specific conditions. Therefore, the previous studies do not have a single basis experience to apply to all mineral deposits.

Based on the above, the aim of the article is to summarize the conducted studies to develop the most general way to simulate the manifestations of rock pressure in the mine workings on the equivalent materials models.

\footnotetext{
* Corresponding author: oleglyub@gmail.com
} 
The world experience shows that the studies of rock pressure manifestations are carried out comprehensively, including the analytical method, the method of physical modeling, and field experiments.

Separate studies in field conditions (complex long-term and expensive) are not enough to justify the regularities of the manifestation of rock pressure with a large variety of mining and geological factors. For the final purposes, all the results of the studies on the models (with the imitation of cleaning works in geometric scale from 1:200 to 1:500, and with the work imitation of supports - on a scale from 1:20 to 1:100) can be corrected by the correction factor as a result of comparison of field and laboratory studies.

The works of foreign authors $[1,2]$ describe the modeling of the excavation site with imitation of strength characteristics similar to the field conditions. The process of bearing pressure zones formation in front of the complex face is studied. When searching for a possible basis of the research, the paper [3], has been taken into account. It describes the mathematical modeling of the system in view of the drift movement behind the longwall. Furthermore, foreign authors [4-6] with reference to local field research note that the length of the reference pressure zones does not exceed $15-20 \%$ of the depth of development, and the values of the reference pressure zones can be 2-4 times greater than the hydrostatic ones.

The authors of the works [8,9] notice that values of a roof sinking in conveyor and ventilating drifts on distance from a longwall on $160 \mathrm{~m}$ make $140-160 \mathrm{~mm}$.

The authors of the works $[10,11]$ notice problem-solving complexity of effective and safe mining due to simultaneous influence of a number of mining-geological and mining engineering factors that is caused mainly by high influence variability of separate factors in space and in time.

The analysis of the carried out researches has shown that during carrying out the laboratory tests of rock pressure redistribution in workings of a various configuration and at various kinds of support (anchors, wood, metal) was not investigated simultaneously (for comparison).

The branch of KuzSTU in Prokopievsk has accumulated a wide experience in imitation of coal seams development in different contexts; on the basis of the carried out researches a significant number of works have been published and patents for new methods of modeling and development of steeply falling seams have been obtained.

\section{Materials and methods}

In the research work the authors used hydraulic sensors (mesdozes) to fix the rock pressure redistribution in three simultaneously carried out workings of different configuration. For the model, more elastic mesdozes than usual were found, with the possibility to increase the coefficient of concentration of rock pressure in 2,5 ... 3,0 times.

Fig. 1 shows the model before carrying out three workings in the gypsum-sandy massif in the geometric scale of 1:100, the seam 34 of the mine "Tagaryshskaya" was simulated.

Fig. 1 presents: 1 - coal seam with the capacity of $\mathrm{m}=2,8 \ldots 3,2 \mathrm{~m} ; 2,3$ - contours of the planned excavations (trapezium and inverted trapezium); 4 - the contour of rectangular section with the planned loosening zone on the right side of the roof; 5 - indicators of clock type with the division price of $0.01 \mathrm{~mm}$ on the anchors laid at the time of model formation at a distance of $4.0 \mathrm{~m}$ from the seam (1 row) and at a distance of $8.0 \mathrm{~m}$ from the seam (2 row); 6 - soil of the seam (fine-grained siltstone $f=3 \ldots 4$ ); 7 - direct seam roof (finegrained siltstone $\mathrm{f}=3 \ldots 4, \mathrm{~m}=4 \ldots 7 \mathrm{~m}$ ); 7 ' - main seam roof (fine-grained siltstone $\mathrm{f}=$ $3 \ldots 4, \mathrm{~m}=9 \ldots 18 \mathrm{~m}$ ), 8 - mesdose in the seam roof to control a given depth (in the body of the seam the mesdose was located at a depth of $1,5 \mathrm{~m}$ from the soil - one in the middle of the workings and 3 mesdozes outside the contour on the right side, the tubes with liquid 
from these mesdozes were opened before the simulation of the depth $\mathrm{H}=300 \mathrm{~m}$ and placed on the other side of the model, are not shown in the figure); 9 - fencing for pneumatically loaded cylinders.

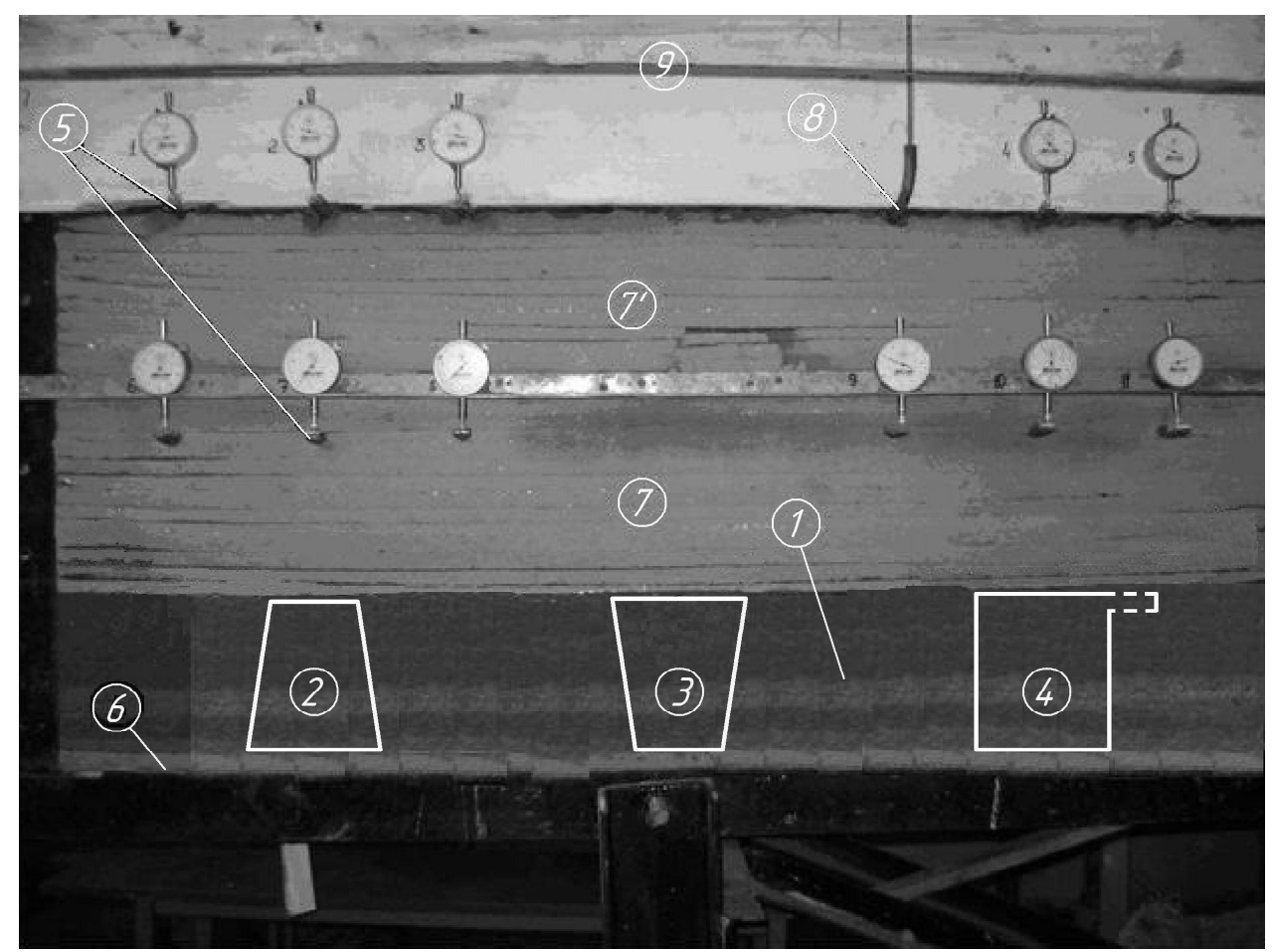

Fig. 1. Excavation model.

This model was formed from equivalent materials to a depth of 1 meter, and then for imitation the necessary depth of mining operations was loaded with the help of pneumoballoons, according to the mechanical similarity conditions of the model and nature:

$$
\sigma_{M}=L_{M} \gamma_{M} /\left(L_{H} \gamma_{H}\right) \sigma_{H}, \mathrm{MPa},
$$

where: $\sigma_{M}$ - model loading at simulated depth, MPa;

$\sigma_{H}$-stress state of the massif at the depth of mining operations, MPa;

$L_{M}$ - required model height in geometric scale, $\mathrm{m}$;

$L_{H}$ - natural depth of mining, m;

$\gamma_{M}$ - bulk weight of rock equivalent materials, MPa;

$\gamma_{H}$ - bulk weight of rocks in nature, MPa.

Since for this model $\gamma_{M} / \gamma_{H}=0.8$, the model load (cylinder pressure) was $\sigma_{M}=0.056$ $\mathrm{MPa}$ to simulate the depth of $\mathrm{H}=300 \mathrm{~m}$. Then, at a given depth, the production of a given section and configuration was carried out, resulting in the formation of unloading zones (in the section of excavations) and high pressure zones (outside the section of excavations). They were fixed with the help of mesdose and a significant number of reapers with indicators of clock type 5, laid during the formation of the model in an array of host rocks and coal according to the developed technique.

\section{Results and discussion}


The results of rock pressure redistribution recorded after excavation are shown in Fig. 2.

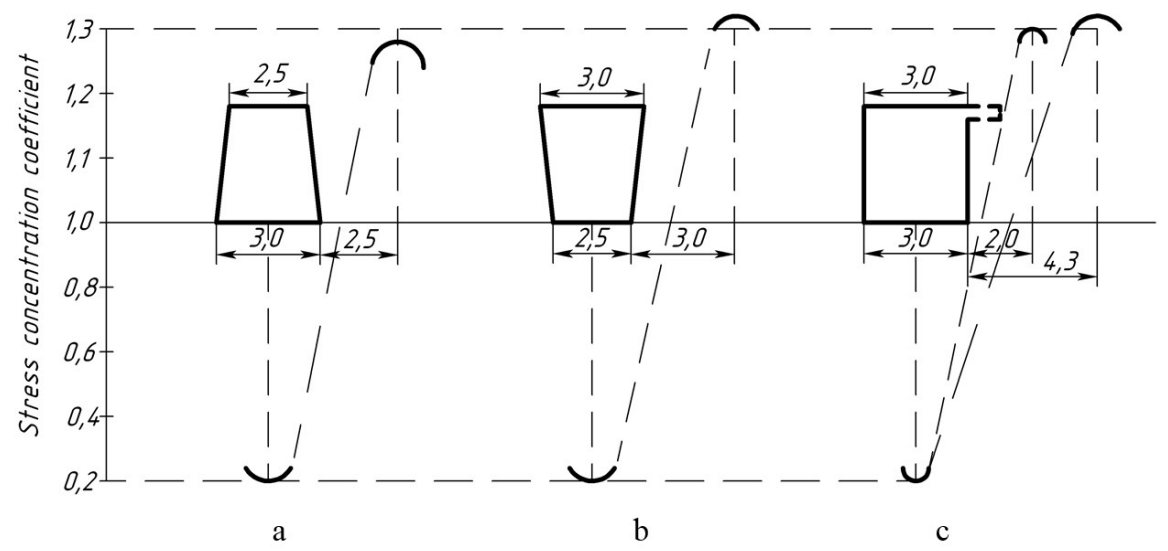

Fig. 2. Results of rock pressure redistribution after excavations in the untouched massif.

As it is shown at Fig. 2, the concentration coefficient of the reference pressure in all cases was about $\mathrm{K}=1.3\left(\gamma_{H}=0.07 \ldots 0.074 \mathrm{MPa}\right)$, and in the soil during unloading the workings the coefficient was about $\mathrm{K}=0.2\left(\gamma_{H}=0.01 \ldots 0.013 \mathrm{MPa}\right)$, while in the trapezoidal section (normal) concentration coefficient (Fig. 2, a) moved away from the mine site by 2.5 $\mathrm{m}$, in the development of an inverted trapezium type (Fig. 2, b) it moved away from the mine site by $3.0 \mathrm{~m}$, and in the development of a rectangular cross-section (Fig. 2, c) the maximum reference pressure moved by $2.0 \mathrm{~m}$, but in the case of loosening of the coal pillar on the right side of the roof by $2.0 \mathrm{~m}$ the maximum reference pressure moved by $4.3 \mathrm{~m}$ from the mine site. It should be noted that the roofing displacement measured by portable indicators of clock type in terms of nature was 3.2, 6.4 and $3.1 \mathrm{~mm}$ (Fig. 2, a, b and c, respectively), and after loosening the roof in the right corner of the rectangular workings under the roof by $2.0 \mathrm{~m}$, the roof displacement reached $4.4 \mathrm{~mm}$. At the same time, at a distance of $4.0 \mathrm{~m}$ from the roof, the repertoire displacement were not more than $1.5 \mathrm{~mm}$, and at a distance of $8.0 \mathrm{~m}$ from the roof, no repertoire displacement were observed. However, after a long break of 1 month (15 months with a time scale of 1:15), when the pressure in the pneumatic cylinders increased to $0.084 \mathrm{MPa}(\mathrm{K}=1.5)$, the displacement of the roof in the workings increased by $2.3 \ldots 2.6$ times and amounted to 7.3, 16.6 and 11.4 $\mathrm{mm}$ (respectively, Fig. $3 \mathrm{a}, \mathrm{b}$ and c). After that, the loose roofing of workings at the displacement of 16.6 and $11.4 \mathrm{~mm}$ began to laminate and collapse. Repertoire displacement at a distance of $4.0 \mathrm{~m}$ from the roof increased by an average of 1.6 times and amounted to about $2.4 \mathrm{~mm}$, and the second row of repertoire did not move, which led to the decision to simulate the movement of the cleaning face with the creation of zones of high rock pressure, unloading zones and stabilization zones.

The simulation of excavations was carried out without fastening on this model, because the main task was to check the operability of new elastic mesdoses and to study the possibility of pushing the maximum support pressure away from the mine contour, with the possibility to conduct further studies at a given time. It was necessary to determine the allowed distance of the roof span exposure in the workings to have the possibility of loosening the massif to create zones of unloading the massif in the roof or sides of workings without deformation and destruction of their supports.

The analysis of the results (Fig. 2) has shown that with the growth of the roof exposure in the workings, the maximum reference pressure is shifted away from the workings contour with the simultaneous increase of the concentration coefficient. In this regard, there is a need for further study of the impact of exposures around the excavation contour at the 
soil and mine sides, taking into account different configurations for the entire service life of the supports. In view of the above, a new "Method of imitation of rock pressure on models of equivalent materials" has been developed, illustrated in Fig. 3.

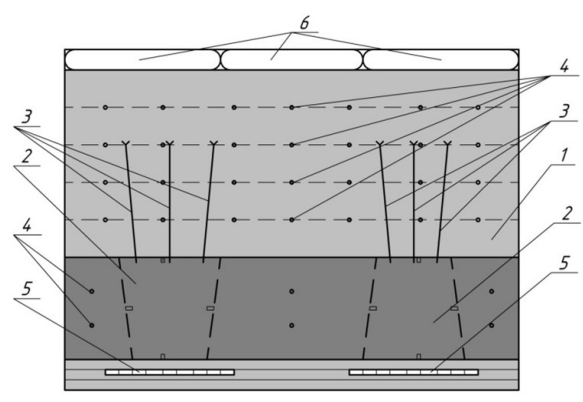

a

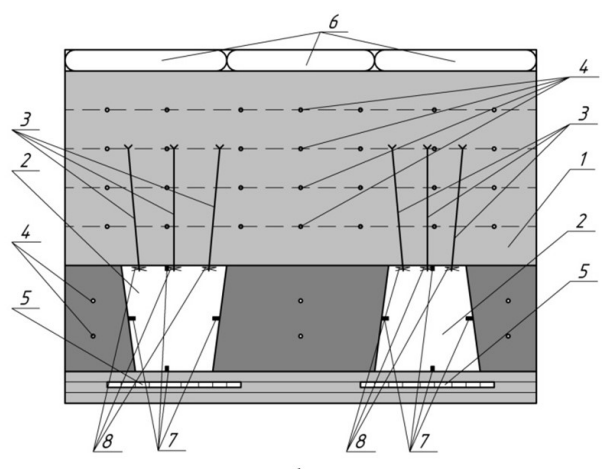

$\mathrm{b}$

Fig.3. Model in accordance with the proposed method: a - prepared for mining, b - after the comparable workings at a given depth of mining.

Fig. 3 presents: 1 - the roof of the seam; 2 - profiles of the workings to be carried out; 3 - anchors laid during the formation of models without tops $8 ; 4$ - repertoires for recording the displacement of the massif around workings; 5 - mesdozes in the soil of workings to fix the left-right redistribution of rock pressure. 6 - cylinders of pneumatic loading; 7-circuit repertoires in excavations for fixation of contour shifts in the direction of "soil-roof" and "side-side"; 8 - top supports attached to anchors 3 after working out (with or without pliable elements, are not shown).

The essence of the method Fig. 3 is as follows:

Several excavations of a given cross-section and different configurations are carried out at a given depth. As a result unloading zones (in each excavation) are formed, that are fixed with the help of mesdozes 5 and a significant number of repertoires 4 , laid during the model forming, the displacement is recorded with the help of clock type indicators (see Fig. 1). After excavation, they are used to lay contour repertoires 7 (soil-roof and side-side) and to construct support. In this case, anchors 3 with attached tops 8 , with or without supple elements (Fig. 3 is not shown), begin to act as a retention (cross-linking) of the roof, and then simulate the approach of the bottom-hole treatment plant to the measuring station with the simulation of ELV zones of unloading zones and stabilization zones. This is done by changing the pressure in the pneumatic loading cylinders, according to the values of redistribution of rock pressure obtained on the models of small scale or during field studies during the movement of the cleaning face line. In this way, the work of various supports is being studied in various mining and geological conditions from the moment of their carrying out and throughout their service life, taking into account the time scale.

As a result of the researches, especially when the soil is prone to swell, it is possible to recommend reasonably the rational parameters of supports preventing (reducing) of workings soil swelling when coal and ore deposits are not uncovered.

\section{Conclusion}

As a result of the analysis and simulation of various configuration workings in the untouched massif, a new way of imitation of rock pressure manifestations in workings on models of equivalent materials was developed. It is established that with the help of new elastic hydraulic sensors it is possible to fix redistributions of rock pressure in preparatory 
workings from the beginning of their carrying out till the end of service life simultaneously in several compared configurations with various types of supports (anchors, wood, metal), allowing to raise stability of the massif of containing rocks. This is especially important when there are rock excavations in the soil that are prone to swell. The proposed method can be used to study the loads on the support of preparatory workings not yet uncovered coal and ore deposits of minerals.

\section{References}

1. V. Sotskov, I. Saleev, Min. of Min. Dep (CRC Press/Balkema, Leiden, 2013)

2. I. B. Tulu, G. S. Esterhuizen, D. Gearhart, T. M. Klemetti, K. M. Mohamed, D. W. H. $\mathrm{Su}$, Int. J. of Min. Sc. and Techn, 28 (2018)

3. K. V. Stefan, Glukauf, 1, 102 (2004)

4. K. D. Erer, A. Heidarieh-Zadeh, Min. Sc. and Techn., 2, 3 (1985)

5. S. S. Peng, Longwall Mining (West Virginia University, Parkersberg, 2006)

6. P. H. Lu, Ground Control Study of Mechanized Longwall Coal Operation in West Virginia (West Virginia University, Parkersberg, 1985)

7. Prediction of shears zones associated with outbursts in coal mines (Lama R.D.S., SheffieId, 1987)

8. L. Fu-chen, Zh. Wei, S. Ai-hua, The El. J. of Geotech. Eng., 18 (2013)

9. P. Peng-Zhi, J. Rutqvist, F. Xia-Ting, Y. Fei, J. Quan, Rock Mech. and Rock Eng., 47, $6(2014)$

10. J. L. Luo, Unpubl. Thes (West Virginia University, Parkersberg, 1997)

11. C. Mark, Multiple-seam longwall mining in the United States: lessons for ground control (NIOSH, Pittsburgh, 2007) 